Running Head: MOTIVATIONAL VS. METABOLIC

Word Count: 3962

To view the final version of this $($ ) American Psychological Association, SAGE publication go here:

http://dx.doi.org/10.1177/0956797612439069

The Motivational versus Metabolic Effects of Carbohydrates on Self-Control

Daniel C. Molden ${ }^{1}$ Chin Ming Hui ${ }^{1} \quad$ Abigail A. Scholer ${ }^{2}$ Brian P. Meier ${ }^{3}$

Eric E. Noreen ${ }^{3}$ Paul R. D’Agostino ${ }^{3}$ Valerie Martin ${ }^{3}$

${ }^{1}$ Northwestern University

${ }^{2}$ University of Waterloo

${ }^{3}$ Gettysburg College

Corresponding Author:

Daniel C. Molden

Northwestern University

2029 Sheridan Rd.

Evanston, IL 60208

Phone: 1-773-266-0024 Fax: 1-847-491-7859

molden@northwestern.edu 


\begin{abstract}
Self-control is critical for achievement and well-being. However, people's capacity for selfcontrol is limited and becomes depleted through use. One prominent explanation for this depletion is that self-control consumes energy in the form of carbohydrate metabolization and further suggests that ingesting carbohydrates improves self-control. Some evidence has supported this energy model, but given the broad implications of the model for efforts to improve self-control, the present research reevaluated the role of carbohydrates in selfcontrol processes. Four experiments demonstrated that (a) under carefully standardized conditions using precise measurements, exerting self-control did not reduce blood glucose; (b) rinsing one's mouth with, but not ingesting, carbohydrate solutions immediately bolstered self-control and prevented depletion; and (c) carbohydrate rinsing did not itself increase blood glucose. These findings challenge metabolic explanations for the role of carbohydrates in self-control depletion and suggest an alternate motivational mode/ for these and other previously observed effects of carbohydrates on self-control (150 words).
\end{abstract}

Keywords: strength model of self-regulation; ego depletion; glucose and self-control; glucose and mental performance 


\section{The Motivational versus Metabolic Effects of Carbohydrates on Self-Control}

People's effortful regulation of their thoughts and actions, i.e., their self-control, has an enormous impact on their lives. Studies have repeatedly demonstrated that the more selfcontrol individuals typically exercise, the happier, healthier, and more successful they are in their professions and relationships from adolescence to old age (Mischel, Shoda, \& Rodriguez, 1989; Moffitt et al., 2011; Tangney, Baumeister, \& Boone, 2004). Accordingly, researchers have long worked to understand who engages in self-control, and what can be done to improve self-control abilities (Baumeister, Gailliot, DeWall, \& Oaten, 2006; Diamond, Barnett, Thomas, \& Munro, 2007).

One primary challenge to improving self-control is that whenever people exert such control, they appear to draw upon a global pool of self-regulatory resources that is limited and can be depleted. Using the central metaphor of a muscle, researchers have likened this depletion to expending energy during physical activity, which produces temporary "fatigue" and an inability to indefinitely sustain attention and effort (Muraven \& Baumeister, 2000). Consistent with this metaphor, a recent meta-analysis of 83 studies clearly demonstrated that following initial tasks requiring self-control or executive function, performance on subsequent tasks that also require self-control declines, even when the specific skills these two tasks require exist in different modalities (e.g., perceptual monitoring versus logical reasoning; Hagger, Wood, Stiff, \& Chatzisarantis, 2010).

\section{The Energy Model of Self- Control}

The metaphorical conceptualization of self-control as a muscle that becomes less effective with continued use has been enormously influential and has greatly advanced thinking and research in this area. However, some researchers have recently argued that similarities between self-control processes and muscle function are not simply metaphorical (Gailliot \& Baumeister, 2007); just as muscles metabolize simple carbohydrates as their primary fuel, some studies appear to suggest that so too may self-control rely upon 
carbohydrate metabolization (Gailliot et al., 2007; Gailliot, Michelle Peruche, Plant, \& Baumeister, 2009; Masicampo \& Baumeister, 2008). That is, just as physical exertion consumes carbohydrates, these studies imply that exerting self-control depletes the body's carbohydrate stores, and, just as physical activity can be bolstered when carbohydrates are ingested, self-control is also enhanced by carbohydrate intake.

Such an energy model of limited self-control has several wide-ranging implications. For example, individuals with inherited or acquired deficiencies in their metabolization of carbohydrates would presumably face greater challenges in achieving success and wellbeing. Also, in opposition to the current trend of eliminating foods laden with carbohydrates from school or office cafeterias, the availability of such foods could actually help sustain learning and productivity. Carefully evaluating this energy model of self-control is thus broadly important for both public policy and public health and was the primary objective of the present research.

\section{Challenges to the Energy Model and the}

\section{Role of Carbohydrate Metabolization in Self-Control}

The role of carbohydrate metabolization in self-control has not gone unchallenged (Beedie \& Lane, in press; Kurzban, 2010). In addition to questions about the methodology of how such metabolization was assessed, criticisms have also focused on the physiological mechanisms proposed to explain how carbohydrate metabolization presumably fuels selfcontrol (also see Gibson, 2007; Messier, 2004). The specific goals of the present research were thus: (a) to better test whether the behavioral effects of exerting self-control are linked to the metabolization of carbohydrates using an improved methodology, and (b) to evaluate an alternative motivational model to explain findings linking the ingestion of carbohydrates to improved self-control.

Although the relationship between the availability of simple carbohydrates such as glucose in the blood and the utilization of these carbohydrates in the brain is not 
straightforward (Gibson, 2007; Messier, 2004), one piece of evidence for the energy model of limited self-control is that engaging in self-control appears to lower blood glucose levels (Dvorak \& Simons, 2009; Gailliot et al., 2007). However, this finding is not entirely consistent (Kurzban, 2010). One reason for this inconsistency could be that studies linking carbohydrate metabolization to self-control have employed commercially available AccuChek blood glucose monitors (Roche Diagnostics, Basel, Switzerland), which do not possess the precision of formal laboratory assessments (Beedie \& Lane, in press; Khan, Vasquez, Gray, Wians Jr, \& Kroll, 2006). Experiment 1 therefore evaluated how exerting self-control affects both subsequent self-control and blood glucose levels using best-practice laboratory methods.

A second piece of evidence for the energy model of self-control is that ingesting carbohydrates following self-control on one task improves performance on subsequent tasks that also require self-control - i.e., carbohydrate consumption appears to replenish the resources depleted by initial self-control efforts and to sustain future efforts (DeWall, Baumeister, Gailliot, \& Maner, 2008; Gailliot et al., 2007; Gailliot et al., 2009; Masicampo \& Baumeister, 2008). This finding has been more consistent and matches other experiments demonstrating that carbohydrate ingestion boosts performance on mental and physical tasks (Messier, 2004; Riby, 2004), yet multiple questions exist concerning whether these effects are truly due to connections between carbohydrate metabolization and brain function (Beedie \& Lane, in press; Gibson, 2007; Kurzban, 2010; Messier, 2004).

\section{An Alternative to the Energy Model: Motivational Effects of Carbohydrates}

Recently, several researchers have discovered an alternative mechanism by which carbohydrates influence physical effort. Multiple experiments in which participants briefly rinsed their mouths with, but did not ingest, carbohydrate solutions during intense physical activity (e.g., cycling or running time-trials) demonstrated significant increases in performance as compared to participants who rinsed with placebo solutions consisting of 
non-carbohydrate sweeteners (Chambers, Bridge, \& Jones, 2009; see Painelli, Nicastro, \& Lancha, 2010). Indeed, one study demonstrated a greater effect on performance for carbohydrate-rinsing than for carbohydrate-ingestion (Pottier, Bouckaert, Gilis, Roels, \& Derave, 2010). These studies therefore indicate that carbohydrates affect persistence and performance in non-energetic ways.

Furthermore, neuroimaging studies suggest a specific origin for these non-energetic effects: Carbohydrate mouth-rinses activate dopaminergic pathways in the striatum-a region of the brain associated with responses to reward (Kringelbach, 2004)-whereas artificiallysweetened non-carbohydrate mouth-rinses do not (Chambers et al., 2009). Thus, the sensing of carbohydrates in the mouth appears to signal the possibility of reward (i.e., the future availability of additional energy), which could motivate rather than fuel physical effort. In addition, because prolonged physical exertion requires self-control (Morsella, 2005), these studies suggest that carbohydrate ingestion could similarly boost mental activity requiring self-control by influencing people's motivation rather than energy to continue.

To test such motivational effects, Experiments 2 and 3 examined the effects of rinsing one's mouth with carbohydrate or non-carbohydrate solutions on self-control. Moreover, whereas previous studies included a 10-12 minute delay between the ingestion of carbohydrates and secondary self-control tasks, to allow time for metabolization (Gailliot et al., 2007; Gailliot et al., 2009; Masicampo \& Baumeister, 2008), in both of the present experiments, the secondary self-control task immediately followed rinsing before metabolization could possibly occur. In addition, to ensure the generality of the results, different, but equally well-validated, measures and manipulations of executive function and self-control were used in each experiment.

Finally, although Experiments 2 and 3 tested whether carbohydrate ingestion is required to improve self-control, they did not examine whether simply rinsing one's mouth 
with carbohydrates might itself still increase blood glucose from the release of endogenous stores. This question was therefore the focus of Experiment 4.

\section{Experiment 1: Does Self-Control Consume Carbohydrates?}

\section{Method}

Participants. Eighty-five college students (52 females; mean age=19.28, $S D=1.25$ ) participated for course credit or payment. To control for initial blood-glucose levels and potential glycemic response, all participants (a) were required to weigh at least 110 pounds, (b) were instructed to abstain from eating for 4 hours and from vigorous exercise for 24 hours before the experiment, and (c) completed the study between 4-7 PM.

Procedures and materials. Participants first received a baseline assessment of their blood glucose and then performed a perceptual vigilance task requiring either low or high self-control. Next, they received a second assessment of their blood glucose and, finally, completed an anagram task to measure continued exertion of self-control.

To assess blood glucose both before and after the perceptual vigilance task, participants followed the laboratory reference procedures against which all commercial glucose monitors are tested for accuracy (Khan et al., 2006). They placed their hands on a heating pad for two minutes and then gave a small sample of blood taken from their finger via capillary puncture. These samples were analyzed in duplicate with a YSI 2700 Glucose/Lactate Analyzer (Yellow Springs Instruments, Ohio) and converted to mg/dl.

As in many previous studies of self-control depletion, (Baumeister, Bratslavsky, Muraven, \& Tice, 1998; Hagger et al., 2010), for the perceptual vigilance task, participants first received one page of text and were instructed to cross out every "e". Individuals assigned to the low-depletion condition next received another similar page of text with the same instructions. Individuals assigned to the high-depletion condition next received another page of text with a different set of instructions asking them to only cross out "e"s that were not either adjacent to or one letter removed from another vowel. Following these new rules 
requires more vigilant monitoring of the text and inhibition of the practiced response from the first page, and thus the greater expenditure of self-control resources (Baumeister et al., 1998).

As in many previous studies on self-control depletion (Muraven, Tice, \& Baumeister, 1998; see Hagger et al., 2010), following the second assessment of blood glucose, participants performed an anagram task to assess the effects of the perceptual vigilance task on their subsequent self-control. They were instructed to generate as many words as they could from a set of seven letters, and the amount of time they persisted was the primary measure of continued self-control.

\section{Results and Discussion}

Because time spent on the anagram task was skewed (skewness=1.21), analyses were conducted on log-transformed times (Judd \& McClelland, 1989), but for ease of exposition, raw means are reported. Replicating previous research (Hagger et al., 2010), participants in the high-depletion condition $(M=3.80 \mathrm{~min}, S D=2.74)$ persisted less than participants in the low-depletion condition $(M=4.60 \mathrm{~min}, S D=2.41), t(83)=2.09, p=.04, d=.47$.

However, a 2(low vs. high depletion) X 2(pre- vs. post-task) mixed analysis of variance (ANOVA) on blood glucose levels with repeated measures on the second factor revealed no main-effect of depletion or depletion $X$ measurement interaction, $F s(1,83)<2.05, p s>16$. Thus, despite affecting subsequent persistence, initially engaging in greater self-control did not increase carbohydrate metabolization. Indeed, overall, there was a marginally significant increase in blood glucose from pre-task $(M=81.27 \mathrm{mg} / \mathrm{dL}, S D=7.49)$ to post-task $(M=82.39$ $\mathrm{mg} / \mathrm{dL}, S D=8.68), F(1,83)=2.94, p=.09, d=.19$. This increase could perhaps be explained by task-related cortisol release, which increases blood glucose (Miller \& Tyrell, 1995), but cannot be explained by energy models of self-control, which predict decreases in blood glucose. Finally, unlike Gailliot et al. (2007), neither absolute levels of blood glucose following the perceptual vigilance task nor change in blood glucose from before to after the 
task was significantly correlated with anagram persistence in either the high or low depletion conditions, $|r| s<.20, p s>$.17. Thus, Experiment 1, which employed the most sensitive measures of blood glucose available, adds to existing questions about whether the depletion of self-control resources involves carbohydrate metabolization (Beedie \& Lane, in press; Kurzban, 2010), as proposed by the energy model.

\section{Experiment 2: Must Carbohydrates be Metabolized to Bolster Self-Control?}

Experiment 1 failed to support predictions of the energy model of self-control concerning the metabolization of carbohydrates while exerting self-control. Experiment 2 evaluated a second prediction of the energy model: that ingesting carbohydrates provides additional "fuel" for self-control and reduces the depletion of self-control resources. After a task requiring either low or high self-control, participants rinsed their mouths with, but did not ingest, a solution flavored with either a carbohydrate-based or non-carbohydrate-based sweetener. They then immediately performed a second task that required self-control. Any effects of merely rinsing with carbohydrate solutions on bolstering self-regulation would further challenge energy model accounts of this process.

\section{Method}

Participants. Forty-five university students participated for course credit. Data from one participant were eliminated due to extreme responding (4.59 SD above the grand mean) on the baseline self-control measure (see below). The final sample thus consisted of 44 participants (28 females; mean age $=18.84, S D=0.57$ ). All participants abstained from eating for at least 4 hours prior to the experiment and took part between 9am-12pm or between 4$7 \mathrm{pm}$. Time-of-session had no moderating effects on any of the analyses reported (all ps>.28).

Procedures and materials. To control for baseline differences in self-control resources, participants began the experiment by squeezing the handles of a high-tension handgrip together to suspend a wad of paper in the air for as long as possible. Persistence 
on this task despite growing discomfort has been widely used in previous studies as an index of self-control ( Muraven \& Slessareva, 2003; see Hagger et al., 2010).

Participants next completed the same perceptual vigilance task as in Experiment 1 in either the low or high depletion condition. Then, following previously established procedures (Chambers et al., 2009; see Painelli et al., 2010), participants in the carbohydrate-rinse condition received a cup with $25 \mathrm{~mL}$ of a $6.4 \%$ table-sugar solution, and participants in the non-carbohydrate-rinse condition received a cup with $25 \mathrm{~mL}$ of a $3.2 \%$ solution of Equal ${ }^{\mathrm{TM}}$, a non-carbohydrate, aspartame-based sweetener approximately $2 x$ as sweet as sugar. They rinsed their mouth with all $25 \mathrm{~mL}$ for 5 seconds and then spit it back into the empty cup.

Immediately after rinsing, participants completed a second trial of the handgrip task, and persistence times served as the measure of their self-control following the depletion and rinsing manipulations. Finally, participants completed the brief mood-introspection scale (Mayer \& Gaschke, 1988), rated the taste of the solution with which they rinsed in terms of its sweetness, refreshingness, and tastiness on 1 (very low) to 7 (very high) scales ( $\alpha=.58)$, and reported what they thought was used to flavor the solution.

\section{Results and Discussion}

Because, in this experiment, persistence times were not highly skewed (skewness $=.75$ ), untransformed data was used for all analyses (Judd \& McClelland, 1989). A 2(low vs. high depletion) $X 2$ (carbohydrate vs. non-carbohydrate rinse) between-participants analysis of covariance (ANCOVA) was performed on the second persistence task with the first persistence task included as a covariate. Results revealed only a significant interaction, $F(1,39)=4.54, p=.04$.

Figure 1 shows that participants rinsing with the non-carbohydrate solution displayed significantly reduced persistence in the high- versus the low-depletion condition, $F(1,39)=6.60, p=.01, d=.77$, replicating the typical depletion of self-control (Hagger et al., 2010). However, rinsing with the carbohydrate solution eliminated differences between the 
high- and low-depletion conditions, $F(1,39)=0.22, p=.64, d=.17$. Furthermore, within the highdepletion condition, rinsing with the carbohydrate solution produced significantly greater persistence than rinsing with the non-carbohydrate solution, $F(1,39)=4.12, p=.05, d=.63$, whereas the rinse manipulation had no effect in the low-depletion condition, $F(1,39)=0.90$, $p=.35, d=.28$. Thus, previous effects of carbohydrates on depleted self-control (Gailliot et al., 2007; Gailliot et al., 2009; Masicampo \& Baumeister, 2008) were replicated even when carbohydrates were not ingested and when there was not sufficient time for metabolization (cf. Chambers et al., 2009).

No differences were found in participants' mood or ratings of the taste of the solution, $F s(1,40)<1.43, p s>.24, d s<.36$. Overall, when guessing the source of the flavor for the solution with which they rinsed, $65 \%$ said sugar, $23 \%$ said some other type of natural flavoring (e.g., fruit, tea), $7 \%$ said artificial sweetener, and $5 \%$ said that they did not know. Guesses did not differ based on the actual sweetener (table sugar vs. aspartame) that participants received, $\chi^{2}(3, N=44)=4.83, p=.18$. Experiment 2 thus indicated that effects of carbohydrates on self-control are not necessarily related to metabolic consumption, as proposed by the energy model, and can operate through non-energetic mechanisms.

\section{Experiment 3: Must Carbohydrates be Metabolized to Bolster Cognitive as well as}

\section{Physical Control?}

Experiment 2 demonstrated that carbohydrate metabolism is not necessary for persistence on a physical task. Experiment 3 tested whether the same was true for a purely cognitive measure of self-control.

\section{Method}

Participants. Thirty-one college students (22 females; mean age=18.58, SD=0.85) participated for course credit. All participants abstained from eating for at least 4 hours prior to the experiment and took part between 9am-12pm or between 4-7pm. Time-of-session had no moderating effects on any of the analyses reported (all ps>.16). 
Procedure and materials. To control for baseline differences in self-control resources, participants began the experiment by completing the color-word Stroop task (Stroop, 1935). This task involves identifying the color of letter-strings as quickly and accurately as possible; on some trials, the letter-strings form color-words that are incongruent with the display color (e.g., blue displayed in red), which creates response interference. The speed with which people overcome this interference has also been widely used as a measure of executive function and self-control (Gailliot et al., 2007; Richeson, Baird, Gordon, Heatherton, \& Wyland, 2003; see Hagger et al., 2010). Participants completed 24 trials of the task, and were instructed to press a colored response-key that matched the color in which the letters were displayed as quickly as possible but without sacrificing accuracy. Stroop-interference scores were calculated by subtracting mean response-latencies on trials in which letterstrings did not form words (i.e., $x x x x x x$ ) from mean response-latencies on trials in which letter-strings formed color-words incongruent with the display color (Job, Dweck, \& Walton, 2010; Richeson et al., 2003). Higher interference scores thus represent greater failure to overcome response interference and less exertion of self-control.

Participants then performed a different type of perceptual vigilance task frequently used in previous studies examining the depletion of self-control resources (Schmeichel, Vohs, \& Baumeister, 2003; Hagger et al., 2010). They watched a 6-minute video of a woman speaking while a series of words appeared at the bottom of the screen for 10 seconds each. All participants were instructed to keep their attention focused on the woman's face instead of reading the words-i.e., to exert self-control to inhibit their natural orienting-response. Previous research has demonstrated that these instructions produce a relatively high depletion of self-control resources (Hagger et al., 2010).

Next, participants rinsed with either a carbohydrate- or non-carbohydrate-sweetened solution in the same way as Experiment 2 and immediately completed 96 more trials of the Stroop task. Stroop-interference scores on these latter trials served as the primary measure 
of self-control following the depletion and rinsing manipulations. Finally, participants completed the brief mood-introspection scale and rated the taste of the solution with which they rinsed in the same way as Experiment 2.

\section{Results and Discussion}

Because, in this experiment, Stroop-interference scores were not highly skewed (skewness=.69), untransformed data was used for all analyses. A one-way ANCOVA on the second Stroop task, with the first Stroop task included as a covariate, revealed that interference was significantly lower following carbohydrate than non-carbohydrate rinsing, $F(1,28)=5.02, p=.03, d=.73$, as displayed in Figure 2. Again, there were no differences in the valence or arousal of participants' mood or in ratings of the taste of the solution, $F s(1,29)<1.55, p s>.22, d s<.45$. Experiment 3 thus replicated Experiment 2 and further indicated that, because these effects emerge immediately and in the absence of ingestion, metabolization is not necessary for carbohydrates to bolster self-control, which runs contrary to the energy model of self-control.

\section{Experiment 4: Does Rinsing with Carbohydrates Release Endogenous Energy Stores?}

In Experiments 2 and 3 carbohydrates were never ingested and not enough time passed for metabolization; the observed effects of carbohydrates on self-control thus appear to be due to non-energetic mechanisms. However, rinsing one's mouth with carbohydrates could perhaps increase blood glucose by immediately prompting the greater release of endogenous carbohydrate stores. If this type of mechanism were responsible for the results of our experiments, it would still be broadly consistent with the energy model of self-control. Therefore, Experiment 4 directly tested the effects of rinsing with a carbohydrate solution on blood-glucose levels.

\section{Method}

Participants. Twenty college students ( 11 females; mean age $=19.30$ years, $S D=1.26$ ) participated in the study for course credit or payment. As in Experiment 1, to control for initial 
blood-glucose levels and potential glycemic response, all participants (a) were required to weigh at least 110 pounds, (b) were instructed to abstain from eating for 4 hours and from vigorous exercise for 24 hours before the experiment, and (c) completed the study between 4-7 PM.

Procedures and materials. To assess whether carbohydrate rinsing affected blood glucose levels, all participants received $350 \mathrm{~mL}$ of a $21.4 \%$ glucose solution (in the form of the glucose polymer maltodextrin). This was a substantially greater concentration and quantity of solution than what was used in the previous experiments and was designed to provide a strong test of the endogenous release hypothesis. In the ingestion condition, participants drank the whole solution. In the rinse condition, participants took mouthfuls of the solution, swished it in their mouths for five seconds and then spit it into another empty cup. They repeated these steps several times until they had rinsed with the entire volume of the solution. Following ingestion or rinsing, participants completed unrelated filler tasks for 12 minutes. Blood glucose levels were assessed prior to rinsing or ingestion and after the 12-minute delay using the same laboratory procedures as described in Experiment 1.

\section{Results and Discussion}

A 2(ingestion vs. rinse) $\times 2$ (pre- vs. post-test) mixed ANOVA on blood glucose levels with repeated measures on the second factor revealed an interaction, $F(1,18)=52.06$, $p<.001$. Although blood glucose of course increased substantially for participants ingesting carbohydrates $\left(M_{\text {pre }}=84.10 \mathrm{mg} / \mathrm{dl}, S D_{\text {pre }}=6.76 ; M_{\text {post }}=113.97 \mathrm{mg} / \mathrm{dl}, S D_{\text {post }}=15.69\right)$, $F(1,18)=119.57, p<.001, d=2.58$, it did not increase for participants rinsing with carbohydrates $\left(M_{\text {pre }}=81.78 \mathrm{mg} / \mathrm{dl}, S D_{\text {pre }}=6.01 ; M_{\text {post }}=83.78 \mathrm{mg} / \mathrm{dl}, S D_{\text {post }}=9.23\right), F(1,18)=0.53$, $p=.47, d=.17$.

\section{General Discussion}

Altogether, the four experiments presented here challenge energy models of selfcontrol. Participants exerting greater self-control persisted less on subsequent tasks, but, 
when using the most sensitive measures available, did not show any evidence of increased carbohydrate metabolization. Furthermore, participants who rinsed their mouths with, but did not ingest, carbohydrate solutions showed immediate boosts in self-control, and rinsing itself did not increase blood glucose levels. These findings are all more consistent with a motivational rather than a metabolic role of carbohydrates in self-control (Painelli et al., 2010).

Although our results demonstrate that carbohydrate metabolization is not necessary to sustain self-control, they do not eliminate the possibility that in certain circumstances such metabolization could benefit effort and performance. It is also possible that sustained rinsing with carbohydrates without ingestion has diminishing effects over time. However, given (a) the inconsistent findings on how blood glucose levels are influenced by mental effort, and (b) clear evidence for alternative mechanisms presented here and elsewhere (Beedie \& Lane, in press; Kurzban, 2010; Painelli et al., 2010), we believe a motivational rather than a metabolic model of carbohydrate effects on self-control offers a superior explanation for the available data.

Another reason to question energy models of self-control is that motivational models also better explain many other findings concerning the depletion of self-control that are unrelated to carbohydrates. For example, studies show that the depleting effects of initial efforts at self-control are reversed by increased incentives for performance on subsequent tasks or greater positive affect (Muraven \& Slessareva, 2003; Tice, Baumeister, Shmueli, \& Muraven, 2007). Depletion is also increased by mere perceptions of self-control effort (Clarkson, Hirt, Jia, \& Alexander, 2010; Wan \& Sternthal, 2008) or expectations of future needs for self-control (Muraven, Shmueli, \& Burkley, 2006) and occurs only when people themselves believe that self-control abilities are limited (Job et al., 2010). Thus, although engaging in self-control often leaves people less willing to subsequently exert further self- 
control (or more conscious about conserving what they believe is a limited resource), it does not leave them without the energy to do so when properly motivated.

In conclusion, the present research helps to clarify the psychological and physiological mechanisms responsible for declining self-control following continued exertion even when changing tasks or goals. Findings indicating that this decline is better explained by deficits in motivation rather than energy or ability suggest the possibility of new, promising interventions. Indeed, interventions focused on sustaining or altering self-control motivations could be developed to increase self-control and improve people's outcomes throughout their lives. 


\section{References}

Baumeister, R. F., Bratslavsky, E., Muraven, M., \& Tice, D. M. (1998). Ego depletion: Is the active self a limited resource? Journal of Personality and Social Psychology, 74, $1252-1265$.

Baumeister, R. F., Gailliot, M., DeWall, C. N., \& Oaten, M. (2006). Self-regulation and personality: How interventions increase regulatory success, and how depletion moderates the effects of traits on behavior. Journal of Personality, 74, 1773-1802.

Beedie, C. J., \& Lane, A. M. (in press). The role of glucose in self-control: Another look at the evidence and an alternative conceptualization. Personality and Social Psychology Review.

Chambers, E. S., Bridge, M. W., \& Jones, D. A. (2009). Carbohydrate sensing in the human mouth: effects on exercise performance and brain activity. Journal of Physiology, $587,1779-1794$.

Clarkson, J. J., Hirt, E. R., Jia, L., \& Alexander, M. B. (2010). When perception is more than reality: The effects of perceived versus actual resource depletion on self-regulatory behavior. Journal of Personality and Social Psychology, 98, 29-46.

DeWall, C. N., Baumeister, R. F., Gailliot, M. T., \& Maner, J. K. (2008). Depletion makes the heart grow less helpful: Helping as a function of self-regulatory energy and genetic relatedness. Personality and Social Psychology Bulletin, 34, 1653-1662.

Diamond, A., Barnett, W. S., Thomas, J., \& Munro, S. (2007). Preschool program improves cognitive control. Science, 318, 1387-1388.

Dvorak, R. D., \& Simons, J. S. (2009). Moderation of resource depletion in the self-control strength model: Differing effects of two modes of self-control. Personality and Social Psychology Bulletin, 35, 572-583.

Gailliot, M. T., \& Baumeister, R. F. (2007). The physiology of willpower: Linking blood glucose to self-control. Personality and Social Psychology Review, 11, 303-327. 
Gailliot, M. T., Baumeister, R. F., DeWall, C. N., Maner, J. K., Plant, E. A., Tice, D. M., et al. (2007). Self-control relies on glucose as a limited energy source: Willpower Is more than a metaphor. Journal of Personality and Social Psychology, 92, 325-336.

Gailliot, M. T., Michelle Peruche, B., Plant, E. A., \& Baumeister, R. F. (2009). Stereotypes and prejudice in the blood: Sucrose drinks reduce prejudice and stereotyping. Journal of Experimental Social Psychology, 45, 288-290.

Gibson, E. L. (2007). Carbohydrates and mental function: Feeding or impeding the brain? Nutrition Bulletin, 32, 71-83.

Hagger, M. S., Wood, C., Stiff, C., \& Chatzisarantis, N. L. D. (2010). Ego depletion and the strength model of self-control: A meta-analysis. Psychological Bulletin, 136, 495-525.

Job, V., Dweck, C., \& Walton, G. M. (2010). Ego-depletion - Is it all in your head? Implicit theories about willpower affect self-regulation. Psychological Science, 21, 16861693.

Judd, C. M., \& McClelland, G. H. (1989). Data analysis: A model comparison approach. New York: Harcourt Brace Jovanovich.

Khan, A. I., Vasquez, Y., Gray, J., Wians Jr, F. H., \& Kroll, M. H. (2006). The variability of results between point-of-care testing glucose meters and the central laboratory analyzer. Archives of Pathology and Laboratory Medicine, 130, 1527-1532.

Kringelbach, M. L. (2004). Food for thought: hedonic experience beyond homeostasis in the human brain. Neuroscience, 126, 807-819.

Kurzban, R. (2010). Does the brain consume additional glucose during self-control tasks? Evolutionary Psychology, 8, 244-259.

Masicampo, E. J., \& Baumeister, R. F. (2008). Toward a physiology of dual-process reasoning and judgment: Lemonade, willpower, and expensive rule-based analysis. Psychological Science, 19, 255-260. 
Mayer, J. D., \& Gaschke, Y. N. (1988). The experience and meta-experience of mood. Journal of Personality and Social Psychology, 55, 102-111.

Messier, C. (2004). Glucose improvement of memory: A review. European Journal of Pharmacology, 490, 33-57.

Miller, W., \& Tyrell, J. (1995). Endocrinology and metabolism. New York: McGraw Hill. Mischel, W., Shoda, Y., \& Rodriguez, M. I. (1989). Delay of gratification in children. Science, 244, 933-938.

Moffitt, T. E., Arseneault, L., Belsky, D., Dickson, N., Hancox, R. J., Harrington, H., et al. (2011). A gradient of childhood self-control predicts health, wealth, and public safety. Proceedings of the National Academy of Sciences of the United States of America, 108, 2693-2698.

Morsella, E. (2005). The function of phenomenal states: Supramodular interaction theory. Psychological Review, 112, 1000-1021.

Muraven, M., \& Baumeister, R. F. (2000). Self-regulation and depletion of limited resources: Does self-control resemble a muscle? Psychological Bulletin, 126, 247-259.

Muraven, M., Shmueli, D., \& Burkley, E. (2006). Conserving self-control strength. Journal of Personality and Social Psychology, 91, 524-537.

Muraven, M., \& Slessareva, E. (2003). Mechanisms of self-control failure: Motivation and limited resources. Personality and Social Psychology Bulletin, 29, 894-906.

Muraven, M., Tice, D. M., \& Baumeister, R. F. (1998). Self-control as limited resource: Regulatory depletion patterns. Journal of Personality and Social Psychology, 74, 774-789.

Painelli, V. S., Nicastro, H., \& Lancha, A. H., Jr. (2010). Carbohydrate mouth rinse: Does it improve endurance exercise performance? Nutrition Journal, 9, 33. 
Pottier, A., Bouckaert, J., Gilis, W., Roels, T., \& Derave, W. (2010). Mouth rinse but not ingestion of a carbohydrate solution improves 1-h cycle time trial performance. Scandinavian Journal of Medicine and Science in Sports, 20, 105-111.

Riby, L. M. (2004). The impact of age and task domain on cognitive performance: a metaanalytic review of the glucose facilitation effect. Brain Impairment, 5, 145-165.

Richeson, J. A., Baird, A. A., Gordon, H. L., Heatherton, T. F., \& Wyland, C. L. (2003). An fMRI investigation of the impact of interracial contact on executive function. Nature Neuroscience, 6, 1323-1328.

Schmeichel, B. J., Vohs, K. D., \& Baumeister, R. F. (2003). Intellectual performance and ego depletion: Role of the self in logical reasoning and other information processing. Journal of Personality and Social Psychology, 85, 33-46.

Stroop, J. R. (1935). Studies of interference in serial verbal reactions. Journal of Experimental Psychology, 18, 643-662.

Tangney, J. P., Baumeister, R. F., \& Boone, A. L. (2004). High self-control predicts good adjustment, less pathology, better grades, and interpersonal success. Journal of Personality, 72, 271-324.

Tice, D. M., Baumeister, R. F., Shmueli, D., \& Muraven, M. (2007). Restoring the self: Positive affect helps improve self-regulation following ego depletion. Journal of Experimental Social Psychology, 43, 379-384.

Wan, E. W., \& Sternthal, B. (2008). Regulating the effects of depletion through monitoring. Personality and Social Psychology Bulletin, 34, 32-46. 


\section{Acknowledgements}

The first two authors contributed equally to this manuscript. 
Figure Legends

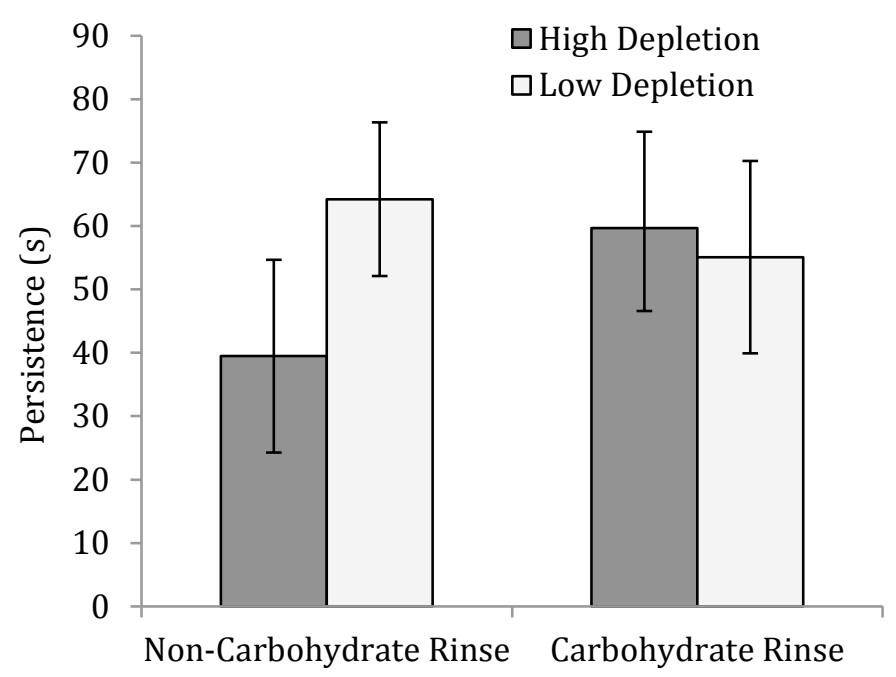

Fig. 1. Persistence on an anagram task immediately following a 5-second mouth-rinse with a solution containing a non-carbohydrate- or carbohydrate-based sweetener. The rinse was administered after an initial perceptual vigilance task that resulted in either low or high depletion of self-control resources. Error bars represent $95 \%$ confidence intervals. 


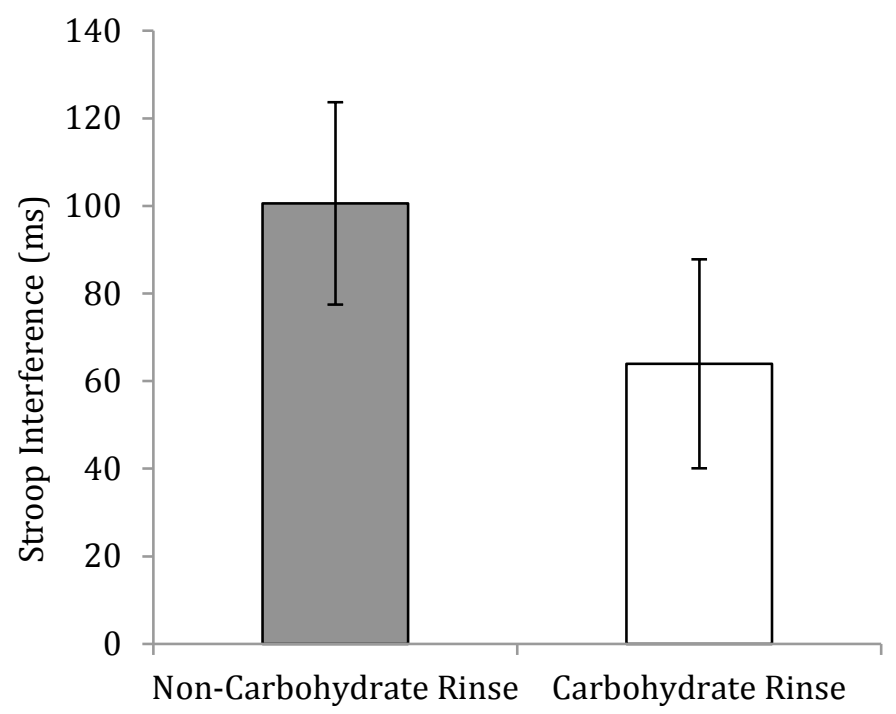

Fig. 2. Interference on incongruent trials of the color-word Stroop task following a 5second mouth-rinse with a solution containing a non-carbohydrate- or carbohydrate based sweetener. The rinse was administered after an initial perceptual-vigilance task that resulted in high depletion of self-control resources. Error bars represent $95 \%$ confidence intervals. 